\title{
ACUTE MASSIVE COLLAPSE OF THE LUNGS: A CASE REPORT
}

\author{
RoBerto L. SIA, M.D.
}

ACUTE MASSIVE COLIAPSE of the lungs is a rare clinical entity which may arise during or very soon after a surgical operation under all forms of anaesthesia. ${ }^{1}$ The history always contains details of increasing difficulty in inflating the patient's lungs, followed by rapid onset of cyanosis and death. Mechanical factors such as a kinked endotracheal tube or mucous plugs should be excluded prior to its diagnosis.

H.H., 66, female, obese, was admitted to the medical ward with preliminary diagnosis of cholecystitis, myocardial insufficiency, and right bronchopneumonia. The patient had an eight-year history of myocardial insufficiency and hypertension. She remained in the ward for two days and was treated with digoxin, guanethodine, spasmoverin, and tetracycline. Her temperature varied between $36^{\circ}$ and $38^{\circ} \mathrm{C}$. during this period.

She had a blood pressure of 180/105; haemoglobin, $13.6 \mathrm{gm}$.; total bilirubin, $2.1 \mathrm{mg}$.; serum protein, $6.1 \mathrm{gm}$.; $\mathrm{K}, 5.3, \mathrm{mEq}$.; $\mathrm{Na}, 149 / \mathrm{mEq}$.; plasma bicarbonate, $20.2 \mathrm{mEq}$.; creatinine, $3.2 \mathrm{mg}$. per cent. An E.C.G. revealed left ventricular hypertrophy and myocardial insufficiency. Chest film showed right pulmonary estasis.

On the third day her condition became worse. She complained of diffuse tenderness on her upper abdomen. A diagnosis of gall-bladder peritonitis was made and the patient was sent to surgery.

Pre-medication was $0.5 \mathrm{mg}$. atropine and $40 \mathrm{mg}$. pethedine intramuscularly one half hour before surgery. Blood pressure prior to anaesthesia was 160/100. Induction was commenced with $200 \mathrm{mg}$. of thiopentone followed by $50 \mathrm{mg}$. of succinylcholine. The lungs were ventilated for a while with oxygen, and the patient was then intubated with a no. 9 cuffed tube. Anaesthesia was maintained with a nitrous-oxide-oxygen mixture in a ratio of 4:2 in a circle absorber system. Muscular relaxation was maintained by intermittent injections of $25 \mathrm{mg}$. of succinylcholine whenever it was required. The patient's blood pressure and pulse during the operation were satisfactory (B.P. between 180 and $200 \mathrm{~mm} . \mathrm{Hg}$ and pulse 90-100). There was indeed perforation of the gall-bladder. The abdominal cavity was washed with saline solution. A rubber tube drain was placed in the foramen of Winslow and closure of the abdominal wall was commenced. It was at this point that no pulse was felt and no blood pressure was recorded. The patient became cyanotic and her pupils started to dilate. Increased resistance to inflation of the lungs was felt. External cardiac massage was immediately started and the lungs were insufflated with oxygen. The patient was placed in Trendelenburg position. Intravenous adrenaline $2 \mathrm{ml}$. 1:1000, $\mathrm{CaCl}_{2} 10$ per cent $4 \mathrm{ml}$, cortisone $100 \mathrm{mg}$, and cedilanid $0.4 \mathrm{mg}$. were given. Her heart fibrillated for a

-Department of Anaesthesia, Oulun Lääninsairaala, Oulu, Finland. 
time and then went into asystole. We defibrillated her three times. After twenty minutes of resuscitation, the patient was lost. Post-mortem findings were: collapsus pulmonis, degeneratio parenchymatosa hepatis, perforatio vesicae fellae, and peritonitis.

\section{Discussion}

The exact mechanism in acute massive collapse of the lungs is not known. It has been suggested that stimulation in the presence of inadequate reflex suppression leads to widespread reflex activity including spasm of the smooth muscle of the bronchioles. ${ }^{1}$ Unfortunately, there is no method of detecting beforehand which patient will develop this condition in order that preventive measures may be taken. The possibility of acute massive collapse of lungs should be kept in mind particularly during light anaesthesia with inadequate reflex suppression, and during brutal manipulation of organs. There is no evidence that those patients who are prone to asthma-either of the allergic type or of the type associated with chronic bronchitis-are more likely to develop this condition, although the condition might be anticipated in those with a hypersensitive bronchial tree.

\section{SUMMARX}

A case of an acute massive collapse of the lungs is reported in a female patient aged 67 who was operated upon for a perforated gall-bladder. The collapse occurred about one hour after induction, with simultaneous cardiac arrest. Cardiac and respiratory resuscitation were performed for twenty minutes but unfortunately the patient was lost. The significant post-mortem finding was the massive collapse of the lungs.

\section{REFERENCE}

1. Wyle \& Churchill-Davidson. A Practice of Anaesthesia. 1st ed., London: Lloyd-Luke (1962), p. 279. 